\title{
Colorectal anastomotic dehiscence: an endoscopic modified-stent solution
}
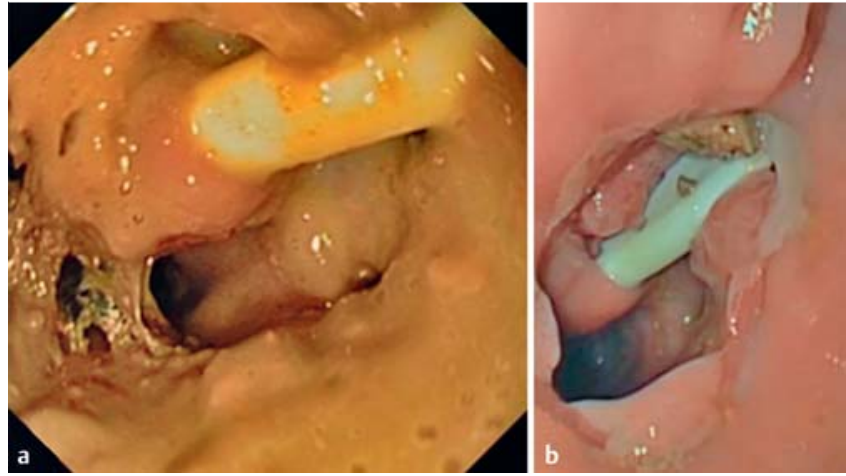

Fig. 1 Post-surgical anastomosis dehiscence in a 64-year-old man after anterior resection for distal rectal cancer. A migrated surgical drain can be seen. a Before lavage; b after lavage.

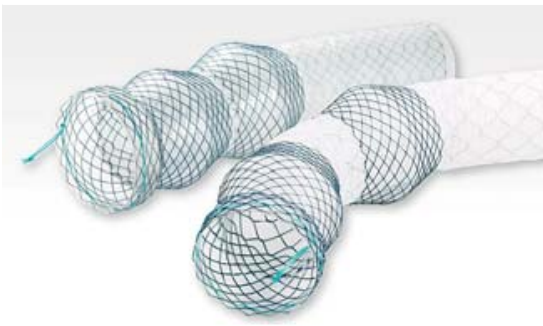

Fig. 2 BETA stent (courtesy of Taewoong Medical).

A 64-year-old man with multiple comorbidities (obesity and metabolic syndrome, dilated cardiomyopathy, type 2 diabetes mellitus, chronic renal insufficiency, obstructive sleep apnea syndrome, and colonic diverticula) underwent anterior resection for distal rectal cancer with protective ileostomy. A few days later, enteral juice was flowing from surgical drains; an urgent endoscopy with fluoroscopy showed the presence of a small (8-mm) anastomotic leak, which was managed conservatively. At 1-month follow-up, endoscopy showed a 75\% anastomotic dehiscence with intraluminal migration of a drain ( $\bullet$ Fig. 1 ). The patient's clinical condition worsened and, after multidisciplinary discussion, an endoscopic transanastomotic fully covered metal stent placement was planned.
The ideal stent had to have a large bore, be sufficiently long, and to have an antimigration system. A large-bore over-thewire stent with a double antimigration system appeared to have these features (head diameter $32 \mathrm{~mm}$, body diameter 24 $\mathrm{mm}$, length $18 \mathrm{~cm}$, BETA stent; Taewoong Medical, Gyeonggi-do, South Korea) ( $\bullet$ Fig.2). As the stent was developed for the treatment of postbariatric surgery leak, specific measures were taken to ensure its antimigration activity and to place the larger stent flare proximally in the colon. On the back table, the stent was released inside a 32-Fr tube; the tube and enclosed stent were then turned round, and the stent was reassembled by inserting the original release system but through the opposite end of the stent (ه Fig. 3).

With the patient under deep sedation, and using endoscopic and radiologic control, the stent was easily released across the anastomotic dehiscence ( $\bullet$ Fig.4). Enteric flow through the abdominal drain immediately stopped, allowing removal of the drain 1 week later. The stent was removed 3 months later, and endoscopy showed complete anastomotic dehiscence resolution ( $\bullet$ Fig.5). The patient remained asymptomatic during the 8-month followup.

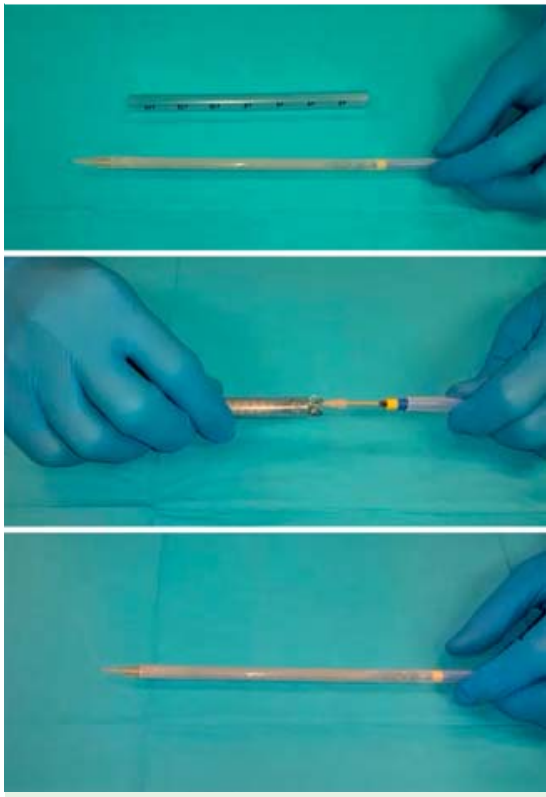

Fig. 3 Reassembling of the stent and delivery system so that the larger stent flare can be positioned proximally in the colon.

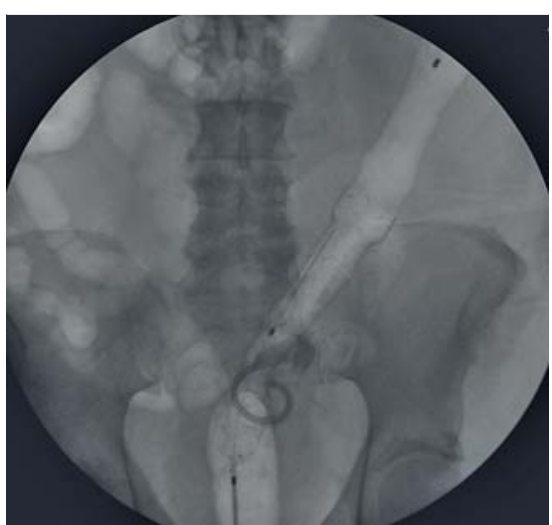

Fig. 4 Over-the-wire insertion of the stent through the rectum. 

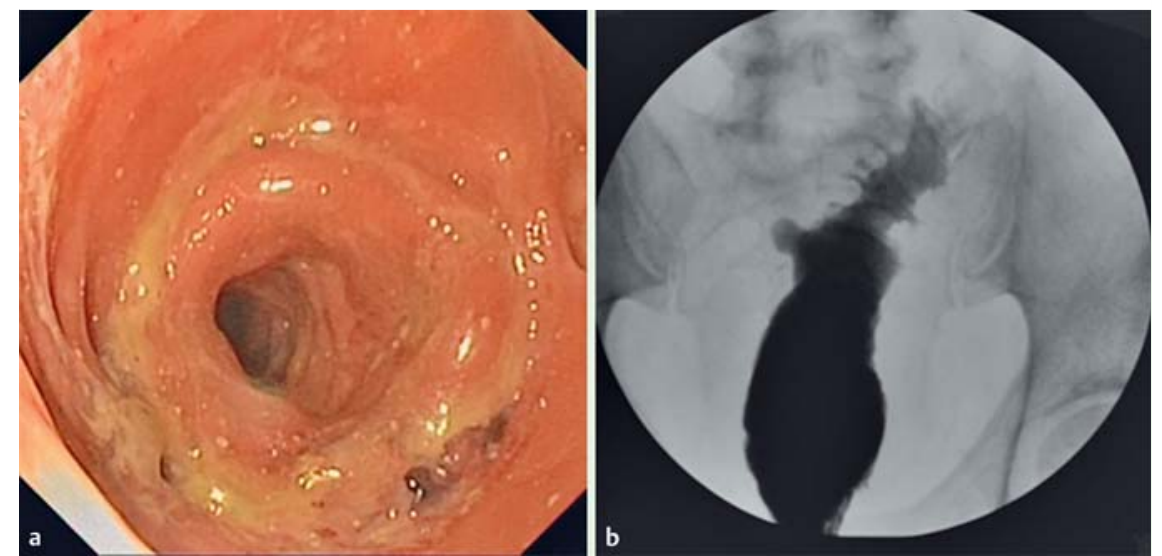

Fig. 5 The sealed anastomosis: a endoluminal view; $\mathbf{b}$ X-ray view.

Anastomotic dehiscence is the "Achilles' heel" of resectional colorectal pathology, and is the most common cause of postoperative morbidity and mortality [1 -3]. This case report describes a new, alternative nonsurgical method for treating a severe complication, such as colorectal anastomotic dehiscence, using a modified large-bore fully covered stent $(\bullet$ Video 1$)$.

\section{Endoscopy_UCTN_Code_TTT_1AQ_2AG}

\section{Competing interests: None}

\section{Antonino Granata ${ }^{1}$, Gabriele Curcio ${ }^{1}$, Dario Ligresti ${ }^{1}$, Ilaria Tarantino ${ }^{1}$, Luca Barresi ${ }^{1}$, Davide Cintorino², Mario Traina ${ }^{1}$}

${ }^{1}$ Endoscopy Service, Department of Diagnostic and Therapeutic Services, IRCCS-ISMETT (Istituto Mediterraneo per i Trapianti e Terapie ad Alta Specializzazione), Palermo, Italy
${ }^{2}$ Abdominal Surgery and Organ Transplantation Unit, Department for the Treatment and Study of Abdominal Diseases and Abdominal Transplantation, IRCCS-ISMETT, Palermo, Italy

\section{References}

1 Oprescu C, Beuran M, Nicolau AE et al. Anastomotic dehiscence (AD) in colorectal cancer surgery: mechanical anastomosis versus manual anastomosis. J Med Life 2012; 5: 444-451

2 Alves A, Panis $Y$, Trancart $D$ et al. Factors associated with clinically significant anastomotic leakage after large bowel resection: multivariate analysis of 707 patients. World J Surg 2002; 26: 499-502

3 Mella J, Biffin A, Radcliffe AG et al. Population-based audit of colorectal cancer management in two UK health regions. Colorectal Cancer Working Group, Royal College of Surgeons of England Clinical Epidemiology and Audit Unit. Br J Surg 1997; 84: 1731 1736

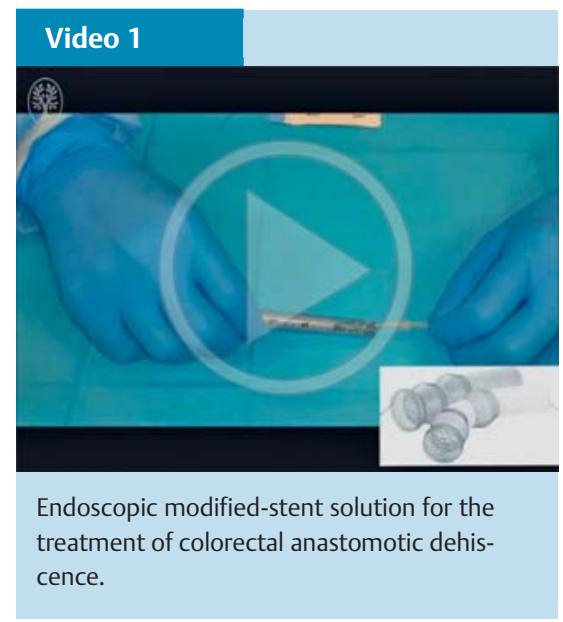

\section{Bibliography}

Dol http://dx.doi.org/

10.1055/s-0042-117221

Endoscopy 2016; 48: E313-E314

(c) Georg Thieme Verlag KG

Stuttgart · New York

ISSN 0013-726X

\section{Corresponding author}

\section{Antonino Granata, MD}

Endoscopy Service

IRCCS-ISMETT

Via Tricomi 5

90127 Palermo

Italy

Fax: +39-091-2192400

agranata@ismett.edu 